\title{
Structure Transformation and Coherent Interface in Large Lattice-Mismatched Nanoscale Multilayers
}

\author{
J. Y. Xie, ${ }^{1}$ F. Wang, ${ }^{2}$ P. Huang, ${ }^{1}$ T. J. Lu, ${ }^{2}$ L. F. Zhang, ${ }^{1}$ and K. W. Xu ${ }^{1}$ \\ ${ }^{1}$ State Key Laboratory for Mechanical Behavior of Material, Xi'an Jiaotong University, Xian 710049, China \\ ${ }^{2}$ State Key Laboratory for Mechanical Structure Strength and Vibration, Xian Jiaotong University, Xian 710049, China \\ Correspondence should be addressed to F. Wang; wangfei@mail.xjtu.edu.cn and P. Huang; huangping@mail.xjtu.edu.cn
}

Received 22 April 2013; Revised 20 June 2013; Accepted 21 June 2013

Academic Editor: Miguel A. Correa-Duarte

Copyright (c) 2013 J. Y. Xie et al. This is an open access article distributed under the Creative Commons Attribution License, which permits unrestricted use, distribution, and reproduction in any medium, provided the original work is properly cited.

\begin{abstract}
Nanoscale Al/W multilayers were fabricated by DC magnetron sputtering and characterized by transmission electron microscopy and high-resolution electron microscopy. Despite the large lattice mismatch and significantly different lattice structures between $\mathrm{Al}$ and W, a structural transition from face-centered cubic to body-centered cubic in Al layers was observed when the individual layer thickness was reduced from $5 \mathrm{~nm}$ to $1 \mathrm{~nm}$, forming coherent Al/W interfaces. For potential mechanisms underlying the observed structure transition and forming of coherent interfaces, it was suggested that the reduction of interfacial energy and high stresses induced by large lattice-mismatch play a crucial role.
\end{abstract}

\section{Introduction}

Nanoscale metallic multilayers have been extensively studied both experimentally and theoretically for their unique mechanical properties as well as size effects [1-10]. For such multilayer systems, the interface always plays a dominant role in plastic deformation, acting as sources and sinks for dislocations $[2,7,11]$. In general, coherent and incoherent interfaces have been identified as the two main types of interface in metallic multilayers, and dislocations can cross the former but not the latter. Accordingly, the type of interface significantly affects the plastic deformation behavior of multilayer system $[7,10]$. To form a coherent interface, the lattice parameter mismatch between two constitute layers should be small, and identical crystal structure is preferred. Therefore, it has been suggested that coherent interfaces hardly exist in a multilayer system possessing simultaneously different crystal structures and large lattice parameter mismatch, for example, $\mathrm{Al} / \mathrm{W}$ multilayers as $\mathrm{Al}$ has face-centered cubic $(\mathrm{fcc}$ ) structure with a lattice parameter of $\sim 0.405 \mathrm{~nm}$ whilst $\mathrm{W}$ has bodycentered cubic (bcc) structure with a lattice parameter of $\sim 0.316 \mathrm{~nm}$. Nonetheless, in this work, we report that coherent interface could indeed form in nanoscale $\mathrm{Al} / \mathrm{W}$ multilayers, although the lattice mismatch between $\mathrm{Al}$ and $\mathrm{W}$ is as high as
$27.95 \%$. The observation of coherent interfaces in nanoscale $\mathrm{Al} / \mathrm{W}$ multilayers may pave a new way for processing novel metallic multilayers having both high strength and ductility.

\section{Experiments}

$\mathrm{Al} / \mathrm{W}$ multilayers with a total thickness of $500 \mathrm{~nm}$ were synthesized using the technique of DC magnetron sputtering at room temperature on oxidized $\mathrm{Si}\left(\begin{array}{ll}1 & 0\end{array}\right)$ substrate. The base pressure prior to sputtering was $6.3 \times 10^{-5} \mathrm{~Pa}$ whilst Ar pressure during sputtering was $0.63 \mathrm{~Pa}$, with deposition rate set as $2.5 \mathrm{~nm} / \mathrm{min}$ for $\mathrm{Al}$ layers and $5 \mathrm{~nm} / \mathrm{min}$ for $\mathrm{W}$ layers. Under such deposition conditions, two samples were fabricated In the first sample, the individual thickness of both $\mathrm{Al}$ and $\mathrm{W}$ layers was nominally equal to $5 \mathrm{~nm}$ (referred to $\mathrm{Al}_{5 \mathrm{~nm}} / \mathrm{W}_{5 \mathrm{~nm}}$ hereafter); in the second sample, the thicknesses of individual $\mathrm{Al}$ and $\mathrm{W}$ layers were set separately as $1 \mathrm{~nm}$ and $5 \mathrm{~nm}$ (referred to $\mathrm{Al}_{1 \mathrm{~nm}} / \mathrm{W}_{5 \mathrm{~nm}}$ hereafter). The cross-sectional microstructures of as-deposited $\mathrm{Al} / \mathrm{W}$ multilayers were investigated using JEOL 2100F transmission electron microscopy (TEM) and high resolution TEM (HRTEM) operated at $200 \mathrm{kV}$. Upon manual polishing, the TEM samples were precisely 
prepared via Gatan Precision Ion Polishing System 691 by using Ar ion.

\section{Results and Discussion}

Figures 1(a) and 1(b) showed bright field TEM images of the cross-sectional morphologies for $\mathrm{Al}_{5 \mathrm{~nm}} / \mathrm{W}_{5 \mathrm{~nm}}$ and $\mathrm{Al}_{1 \mathrm{~nm}} /$ $\mathrm{W}_{5 \mathrm{~nm}}$ multilayers, respectively. Both multilayers exhibited a well-defined layered structure with planar modulation layers, bright layers being $\mathrm{Al}$ and dark layers being $\mathrm{W}$. The electron diffraction (ED) patterns of two multilayers were derived by cross-sectional observation. In Figure 1(d), no Al patterns were detected in the $\mathrm{Al}_{1 \mathrm{~nm}} / \mathrm{W}_{5 \mathrm{~nm}}$ multilayer, while were detected in the $\mathrm{Al}_{5 \mathrm{~nm}} / \mathrm{W}_{5 \mathrm{~nm}}$ multilayer as shown in Figure 1(c).

Figure 2(a) presented HRTEM images of $\mathrm{Al}_{5 \mathrm{~nm}} / \mathrm{W}_{5 \mathrm{~nm}}$ multilayers, and Figures 2(b) and 2(c) showed the Fast Fourier Transformation (FFT) images corresponding to the selected rectangular areas of 1 and 2 as marked in Figure 2(a). For $\mathrm{Al}_{5 \mathrm{~nm}} / \mathrm{W}_{5 \mathrm{~nm}}$ with individual layer thickness of $5 \mathrm{~nm}$, the FFT images indicated that both $\mathrm{Al}$ and $\mathrm{W}$ retained their bulk stable crystal structures, resulting in a stacking sequence of $\mathrm{Al}$ in face-centered cubic structure and $\mathrm{W}$ in bodycentered cubic structure. Further, it was evidenced from the lattice image shown in Figure 2(a) that the interfaces in the $\mathrm{Al}_{5 \mathrm{~nm}} / \mathrm{W}_{5 \mathrm{~nm}}$ multilayers were incoherent.

Combining the $\mathrm{Al}$ and $\mathrm{W}$ layers as a whole to form FFT images as shown in Figures 2(b) and 2(c), one could clearly identify the individual position of each spot for both $\mathrm{Al}$ and W layers, although some spots appeared blurrier than the others. For example, the spot of W (110) was much hazier than that of $\mathrm{Al}$ (111), but the positions corresponding to each spot were separated, and there was an angle of $11^{\circ}$ between two neighboring spots. Moreover, as shown in Figure 2(d), the multilayers exhibited a strong $\mathrm{Al}\{111\} / / \mathrm{W}\{110\}$ growing fiber texture with a Kurdjumov-Sachs orientation [12], similar to that observed for $\mathrm{Al} / \mathrm{Nb}$ multilayers having identical lattice structure (i.e., fcc/bcc) and individual layer thickness as in the present $\mathrm{Al} / \mathrm{W}$ multilayers.

With the Al layer thickness reduced from $5 \mathrm{~nm}$ to $1 \mathrm{~nm}$ whilst that of the $\mathrm{W}$ layer maintained at $5 \mathrm{~nm}$ (i.e., $\left.\mathrm{Al}_{1 \mathrm{~nm}} / \mathrm{W}_{5 \mathrm{~nm}}\right)$, the HRTEM image shown in Figure 3(a) indicated that the Al layers had transformed completely from fcc lattice into bcc lattice, generating accordingly an unusual stacking sequence of bcc Al/bcc W multilayers. Moreover, Figure 3(a) demonstrated clearly that the two different metal layers possessed identical crystal structure and that the wellknown lattice parameter mismatch between bulk $\mathrm{Al}$ and bulk $\mathrm{W}$ vanished in the present $\mathrm{Al}_{1 \mathrm{~nm}} / \mathrm{W}_{5 \mathrm{~nm}}$ multilayers. More importantly, it was seen from Figure 3(a) that the atomic arrangement and slip systems were continuous across the interface. In other words, coherent interface was formed between $\mathrm{Al}$ and $\mathrm{W}$ layers in $\mathrm{Al}_{1 \mathrm{~nm}} / \mathrm{W}_{5 \mathrm{~nm}}$. Further, as shown in Figure 3(c), abundant dislocations similar to those previously reported for nanoscale $\mathrm{Cu} / \mathrm{Nb}$ multilayers [13] were observed in $\mathrm{Al}_{1 \mathrm{~nm}} / \mathrm{W}_{5 \mathrm{~nm}}$ multilayers. The density of dislocation is about $1 \times 10^{17} \mathrm{~m}^{-2}$, and dislocation of intralayer and interface ratio is about $4: 3$.
For $\mathrm{Al}_{1 \mathrm{~nm}} / \mathrm{W}_{5 \mathrm{~nm}}$ multilayers, as the pattern obtained for $1 \mathrm{~nm}$ thick Al layers was too vague, only the FFT image derived from both of the two constitute layers was presented in Figure 3(b). Interestingly, only one series of spots corresponding to the lattice structure of the bcc W layer showed up to be consistent with the HRTEM image of Figure 3(a) where the Al layers were seen to be transformed from fcc to bcc. It should nonetheless be mentioned that spots marked as 2, 3, 5, and 6 in Figure 3(b) were slightly larger than spots 1 and 4, indicating that the transformation appearing to be complete in Figure 3(a) may not be so complete. Slight difference may still exist between the $\mathrm{Al}$ and $\mathrm{W}$ layers in $\mathrm{Al}_{1 \mathrm{~nm}} / \mathrm{W}_{5 \mathrm{~nm}}$, as it was hard to completely eliminate the large lattice mismatch between bulks $\mathrm{Al}$ and $\mathrm{W}$ under the present constrained lattice circumstances, as evidenced along certain orientations of spots $2,3,5$, and 6 .

The present results of $\mathrm{Al}_{1 \mathrm{~nm}} / \mathrm{W}_{5 \mathrm{~nm}}$ multilayers demonstrated that the structure transformation in Al layers played a dominating role in forming coherent $\mathrm{Al} / \mathrm{W}$ interfaces. Numerous models had been proposed to explain structural stabilities in multilayers [14-20]. In particular, the RedfieldZangwill model [15] considering the influence of interfaces on stacking fault energy was found applicable in interpreting phase stability in multilayers. However, the Redfield-Zangwill model only considered phase stability of multilayers consisting of close-packed lattice structures (e.g., fcc and hcp) having similar lattice parameters (e.g., Al/Ti multilayers). In such an fcc/hcp multilayer system, by introducing stacking faults into its parent structure, it was relatively easy to transform an fcc ABCABC stacking sequence into an hcp $A B A B A B$ stacking sequence, or vice versa. For the present $\mathrm{Al} / \mathrm{W}$ multilayers, however, the bulks $\mathrm{Al}$ and $\mathrm{W}$ possessed fcc and bcc lattice structures, respectively. As bcc lattice structure was not close-packed, its stacking sequence was much more complete than that of fcc and hence could not be transformed from fcc by simply introducing stacking faults into the lattice. Consequently, it became apparent that the Redfield-Zangwill model was not applicable to the present $\mathrm{Al}_{1 \mathrm{~nm}} / \mathrm{W}_{5 \mathrm{~nm}}$ multilayer system.

For some nonequilibrium structured multilayers such as $\mathrm{Co} / \mathrm{Cr}[21]$ and $\mathrm{Cu} / \mathrm{Fe}[22]$, it had been found that $\mathrm{Co}$ and $\mathrm{Cu}$ could be transformed from close-packed lattice structure to nonclose-packed one. However, given that the atomic radii of the two constitute layers in both $\mathrm{Co} / \mathrm{Cr}$ and $\mathrm{Cu} / \mathrm{Fe}$ multilayer systems were almost equal, it was quite different from the phase transition occurring in the present $\mathrm{Al}$ layers because of the large lattice mismatch between $\mathrm{Al}$ and $\mathrm{W}$.

From the viewpoint of thermodynamics, the balance between the volumetric and interfacial components of total free energy $[16,17,19,20]$ had been widely used to interpret the phase stability of crystalline materials. For the present $\mathrm{Al} / \mathrm{W}$ multilayer system, when the thickness of Al layers was smaller than a critical value, the crystal structure of $\mathrm{Al}$ tended to adopt the crystal structure of its substrate, that is, $\mathrm{W}$, resulting in a crystalline structure different from the equilibrium structure of $\mathrm{Al}$. Once $\mathrm{Al}$ was deposited onto $\mathrm{W}$, the volumetric free energy gained from accommodating the large lattice-mismatch between the two constitute layers was stored in the multilayers. For $\mathrm{Al}_{1 \mathrm{~nm}} / \mathrm{W}_{5 \mathrm{~nm}}$ multilayers, the 


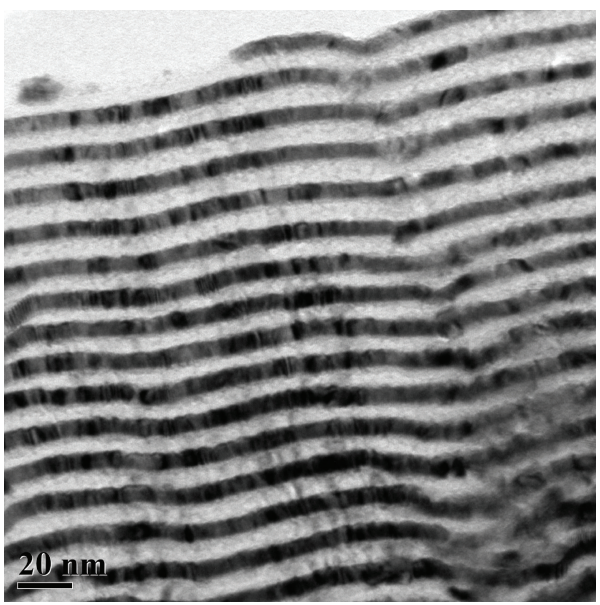

(a)

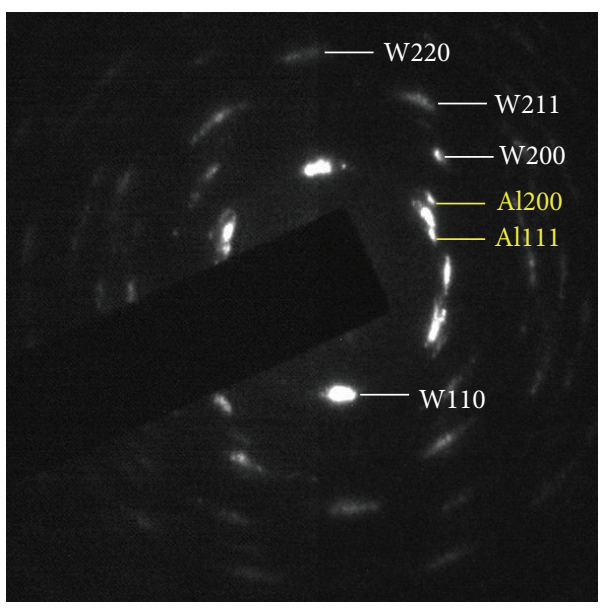

(c)

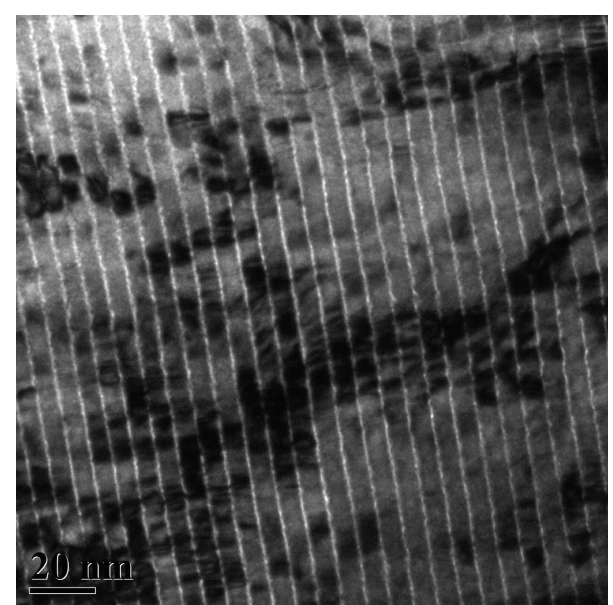

(b)

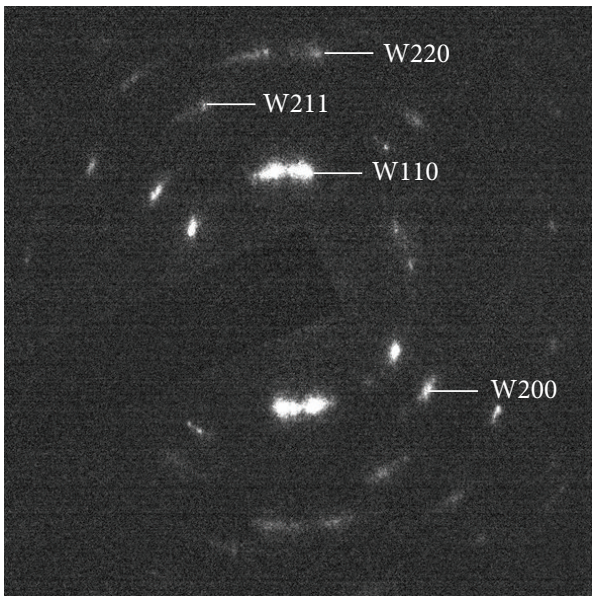

(d)

FIGURE 1: Cross-sectional TEM images of (a) $\mathrm{Al}_{5 \mathrm{~nm}} / \mathrm{W}_{5 \mathrm{~nm}}$ and (b) $\mathrm{Al}_{1 \mathrm{~nm}} / \mathrm{W}_{5 \mathrm{~nm}}$ multilayers showing well-defined layered structures in nanoscale and ED images of (c) $\mathrm{Al}_{5 \mathrm{~nm}} / \mathrm{W}_{5 \mathrm{~nm}}$ and (d) $\mathrm{Al}_{1 \mathrm{~nm}} / \mathrm{W}_{5 \mathrm{~nm}}$ multilayers.

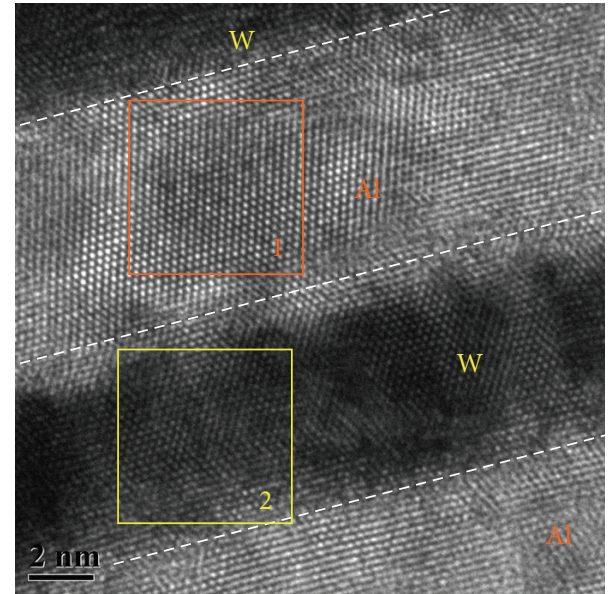

(a)

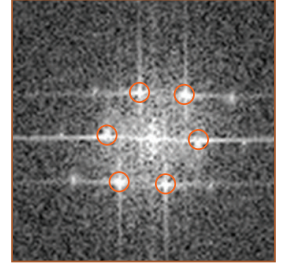

(b)

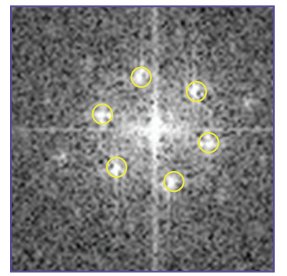

(c)

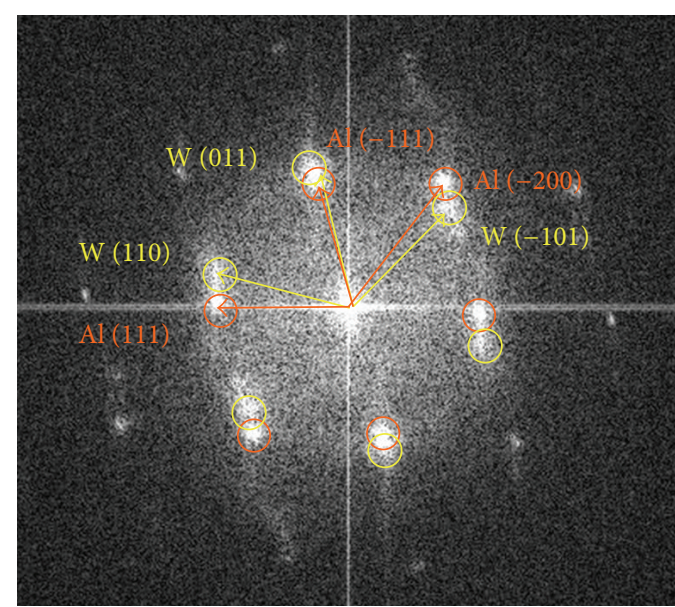

(d)

Figure 2: (a) Presents HRTEM image of $\mathrm{Al}_{5 \mathrm{~nm}} / \mathrm{W}_{5 \mathrm{~nm}}$ multilayers; (b) and (c) are Fast Fourier Transformation (FFT) images of selected rectangular areas " 1 " and "2" marked in (a); and (d) is a combined FFT image derived from $\mathrm{Al}$ and W layers simultaneously. 


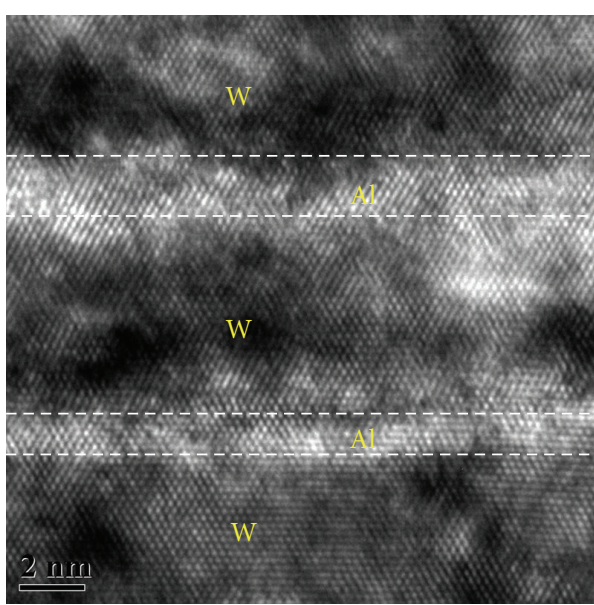

(a)

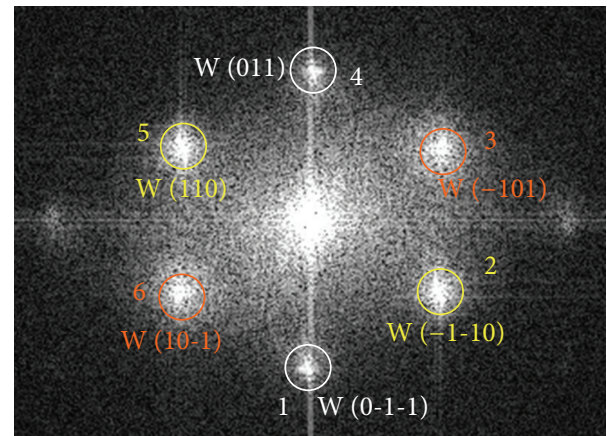

(b)

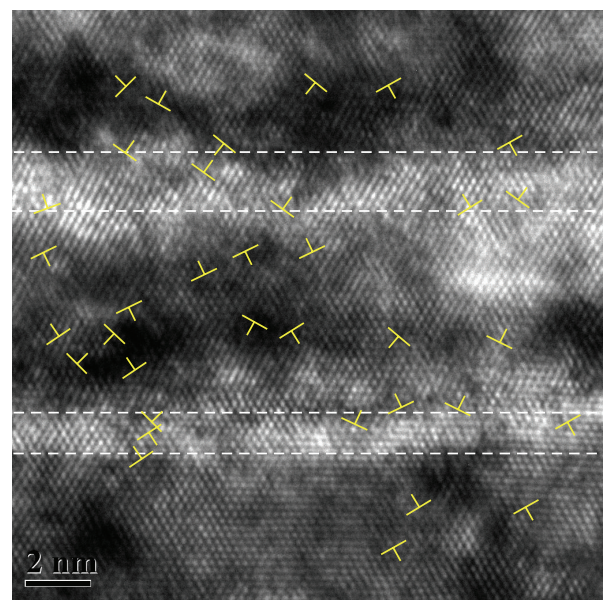

(c)

FIGURE 3: (a) Presents HRTEM image of $\mathrm{Al}_{1 \mathrm{~nm}} / \mathrm{W}_{5 \mathrm{~nm}}$ multilayers; (b) is a combined FFT image derived from both $\mathrm{Al}$ and W layers; and (c) is a dislocation distribution in the multilayer system.

W layers deposited prior to the deposition of $\mathrm{Al}$ served as the template and could confine the lattice structure of the much thinner Al layer, transforming it into bcc Al. This structure transition was driven by a reduction in overall interfacial energy which should be more than compensating the increase of energy from forming metastable phase [23], that is, bcc $\mathrm{Al}$ herein. Moreover, as shown in Figure 3(c), dislocations with high density were present in the $\mathrm{Al}_{1 \mathrm{~nm}} / \mathrm{W}_{5 \mathrm{~nm}}$ system, suggesting that the stresses induced by coherency strain were sufficiently large as the existence and maintaining of dislocations at such small length scale required extremely high stresses [24]. The misfit dislocation is an effective way to decrease volumetric free energy. However, dislocation prefers to nucleate at free surface than interface $[25,26]$. Once dislocation nucleated, it propagates or glides to the interface to relieve misfit strain. Nucleation of dislocations at the free surface during deposition and propagation of these dislocations to the interface are critical steps in the relaxation of coherency strain, as shown in Figure 1. However, if lattice frictional stress in the layer is high, most dislocations may not reach the interface, depending upon the growth temperature and deposition rate. And it will take a higher temperature and longer time to expedite the lattice relaxation process. Appearance of dislocations at interface and in the W layer also indicated the relaxation of coherency strain and minimization of energy. As the thickness of $\mathrm{Al}$ layer is much thinner and softer than that of $\mathrm{W}$ layer, the dislocations easily glide to the interface from inner area of the Al layer, which could be harder in the W layer. Therefore, dislocations mostly appeared at interface and inside the $\mathrm{W}$ layers as observed in Figure 3.

As the individual layer thickness of $\mathrm{Al}$ was increased to $5 \mathrm{~nm}$, the energy derived from lattice fit dropped below the volume energy of the strained Al film. Consequently, the nonequilibrium structure of the Al layer (i.e., bcc Al in the present study) broke down so that it would grow in its equilibrium structure (i.e., fcc), forming incoherent $\mathrm{Al} / \mathrm{W}$ interfaces as observed in $\mathrm{Al}_{5 \mathrm{~nm}} / \mathrm{W}_{5 \mathrm{~nm}}$. In addition, 
few dislocations were observed in the $\mathrm{Al}_{5 \mathrm{~nm}} / \mathrm{W}_{5 \mathrm{~nm}}$ system, indicating that its internal stresses were much smaller than those present in the $\mathrm{Al}_{1 \mathrm{~nm}} / \mathrm{W}_{5 \mathrm{~nm}}$ system.

\section{Summary}

In summary, despite the large lattice mismatch and quite different stacking sequences between $\mathrm{Al}$ and $\mathrm{W}$, we demonstrated in this paper that structural transformation and coherent interface could occur in nanoscale $\mathrm{Al} / \mathrm{W}$ multilayers, depending upon the thickness of the constitute layers. A critical layer thickness appeared to exist, below which an $\mathrm{Al}$ layer would adopt the structure of its template (W layer) driven by the reduction of interfacial energy and high stresses induced by large lattice mismatch; otherwise, the Al layer would transform to its equilibrium structure as both lattice distortion and high internal stresses were released.

\section{Acknowledgments}

This work was financially supported by the National Basic Research Program of China (2010CB631002, 2011CB610306), the National Natural Science Foundation of China (51171141, 51271141), the Program for New Century Excellent Talents in University (NCET-11-0431), Research Fund for the Doctoral Program of Higher Education of China (20120201110001), and the Fundamental Research Funds for the Central Universities.

\section{References}

[1] J. Wang, R. G. Hoagland, X. Y. Liu, and A. Misra, "The influence of interface shear strength on the glide dislocation- interface interactions," Acta Materialia, vol. 59, no. 8, pp. 3164-3173, 2011.

[2] J. Y. Zhang, X. Zhang, R. H. Wang et al., "Length-scaledependent deformation and fracture behavior of $\mathrm{Cu} / \mathrm{X}(\mathrm{X}=\mathrm{Nb}$, $\mathrm{Zr}$ ) multilayers: the constraining effects of the ductile phase on the brittle phase," Acta Materialia, vol. 59, no. 19, pp. 7368-7379, 2011.

[3] Z. W. Zhu, L. Gu, G. Q. Xie et al., "Relation between icosahedral short-range ordering and plastic deformation in $\mathrm{Zr}-\mathrm{Nb}-\mathrm{Cu}-\mathrm{Ni}$ Al bulk metallic glasses," Acta Materialia, vol. 59, no. 7, pp. 28142822, 2011.

[4] Y. P. Li and G. P. Zhang, "On plasticity and fracture of nanostructured $\mathrm{Cu} / \mathrm{X}(\mathrm{X}=\mathrm{Au}, \mathrm{Cr})$ multilayers: the effects of length scale and interface/boundary," Acta Materialia, vol. 58, no. 11, pp. 3877-3887, 2010.

[5] D. Rafaja, C. Schimpf, V. Klemm, G. Schreiber, I. Bakonyi, and L. Péter, "Formation of microstructural defects in electrodeposited Co/Cu multilayers," Acta Materialia, vol. 57, no. 11, pp. 3211-3222, 2009.

[6] S. M. Han, M. A. Phillips, and W. D. Nix, "Study of strain softening behavior of Al-Al3Sc multilayers using microcompression testing," Acta Materialia, vol. 57, no. 15, pp. 4473-4490, 2009.

[7] A. Misra, J. P. Hirth, and R. G. Hoagland, "Length-scaledependent deformation mechanisms in incoherent metallic multilayered composites," Acta Materialia, vol. 53, no. 18, pp. 4817-4824, 2005.

[8] M. A. Phillips, B. M. Clemens, and W. D. Nix, "A model for dislocation behavior during deformation of $\mathrm{Al} / \mathrm{Al} 3 \mathrm{Sc}$ (fcc/L12) metallic multilayers," Acta Materialia, vol. 51, no. 11, pp. 31573170, 2003.

[9] J. Xu, M. Kamiko, Y. Zhou, R. Yamamoto, G. Li, and M. Gu, "Superhardness effects of heterostructure NbN/TaN nanostructured multilayers," Journal of Applied Physics, vol. 89, no. 7, pp. 3674-3678, 2001.

[10] H. M. Zbib, C. T. Overman, F. Akasheh, and D. Bahr, "Analysis of plastic deformation in nanoscale metallic multilayers with coherent and incoherent interfaces," International Journal of Plasticity, vol. 27, no. 10, pp. 1618-1639, 2011.

[11] J. Wang and A. Misra, "An overview of interface-dominated deformation mechanisms in metallic multilayers," Current Opinion in Solid State and Materials Science, vol. 15, no. 1, pp. 20-28, 2011.

[12] N. Li, J. Wang, J. Y. Huang, A. Misra, and X. Zhang, "In situ TEM observations of room temperature dislocation climb at interfaces in nanolayered $\mathrm{Al} / \mathrm{Nb}$ composites," Scripta Materialia, vol. 63, no. 4, pp. 363-366, 2010.

[13] J. Y. Zhang, P. Zhang, X. Zhang et al., "Mechanical properties of $\mathrm{fcc} / \mathrm{fcc} \mathrm{Cu} / \mathrm{Nb}$ nanostructured multilayers," Materials Science and Engineering A, vol. 545, pp. 118-122, 2012.

[14] R. Bruinsma and A. Zangwill, "Structural transitions in epitaxial overlayers," Journal de Physique, vol. 47, no. 12, pp. 20552073, 1986.

[15] A. C. Redfield and A. M. Zangwill, "Stacking sequences in closepacked metallic superlattices," Physical Review B, vol. 34, no. 2, pp. 1378-1380, 1986.

[16] S. A. Dregia, R. Banerjee, and H. L. Fraser, "Polymorphic phase stability in thin multilayers," Scripta Materialia, vol. 39, no. 2, pp. 217-223, 1998.

[17] R. Banerjee, X.-D. Zhang, S. A. Dregia, and H. L. Fraser, "Phase stability in Al/Ti multilayers," Acta Materialia, vol. 47, no. 4, pp. 1153-1161, 1999.

[18] P. P. Chattopadhyay, P. M. G. Nambissan, S. K. Pabi, and I. Manna, "Polymorphic bcc to fcc transformation of nanocrystalline niobium studied by positron annihilation," Physical Review B, vol. 63, no. 5, Article ID 054107, 2001.

[19] G. B. Thompson, R. Banerjee, S. A. Dregia, and H. L. Fraser, "Phase stability of bcc Zr in Nb/Zr thin film multilayers," Acta Materialia, vol. 51, no. 18, pp. 5285-5294, 2003.

[20] J. C. Li, W. Liu, and Q. Jiang, "Bi-phase transition diagrams of metallic thin multilayers," Acta Materialia, vol. 53, no. 4, pp. 1067-1071, 2005.

[21] N. Metoki, W. Donner, and H. Zabel, "Grazing-incidence x-rayscattering study of (001)-oriented high-quality epitaxial Co/Cr superlattices," Physical Review B, vol. 49, no. 24, pp. 17351-17359, 1994.

[22] Z. Q. Wang, S. H. Lu, Y. S. Li, F. Jona, and P. M. Marcus, "Epitaxial growth of a metastable modification of copper with body-centered-cubic structure," Physical Review B, vol. 35, no. 17, pp. 9322-9325, 1987.

[23] R. Banerjee, X.-D. Zhang, S. A. Dregia, and H. L. Fraser, "Phase stability in Al/Ti multilayers," Acta Materialia, vol. 47, no. 4, pp. 1153-1161, 1999.

[24] V. Yamakov, D. Wolf, M. Salazar, S. R. Phillpot, and H. Gleiter, "Length-scale effects in the nucleation of extended dislocations in nanocrystalline Al by molecular-dynamics simulation," Acta Materialia, vol. 49, no. 14, pp. 2713-2722, 2001.

[25] J. Narayan, "Recent progress in thin film epitaxy across the misfit scale," Acta Materialia, vol. 61, no. 8, pp. 2703-2724, 2013. 
[26] S. Sharan and J. Narayan, "Strain relief mechanisms and the nature of dislocations in GaAs/Si heterostructures," Journal of Applied Physics, vol. 66, no. 6, pp. 2376-2380, 1989. 

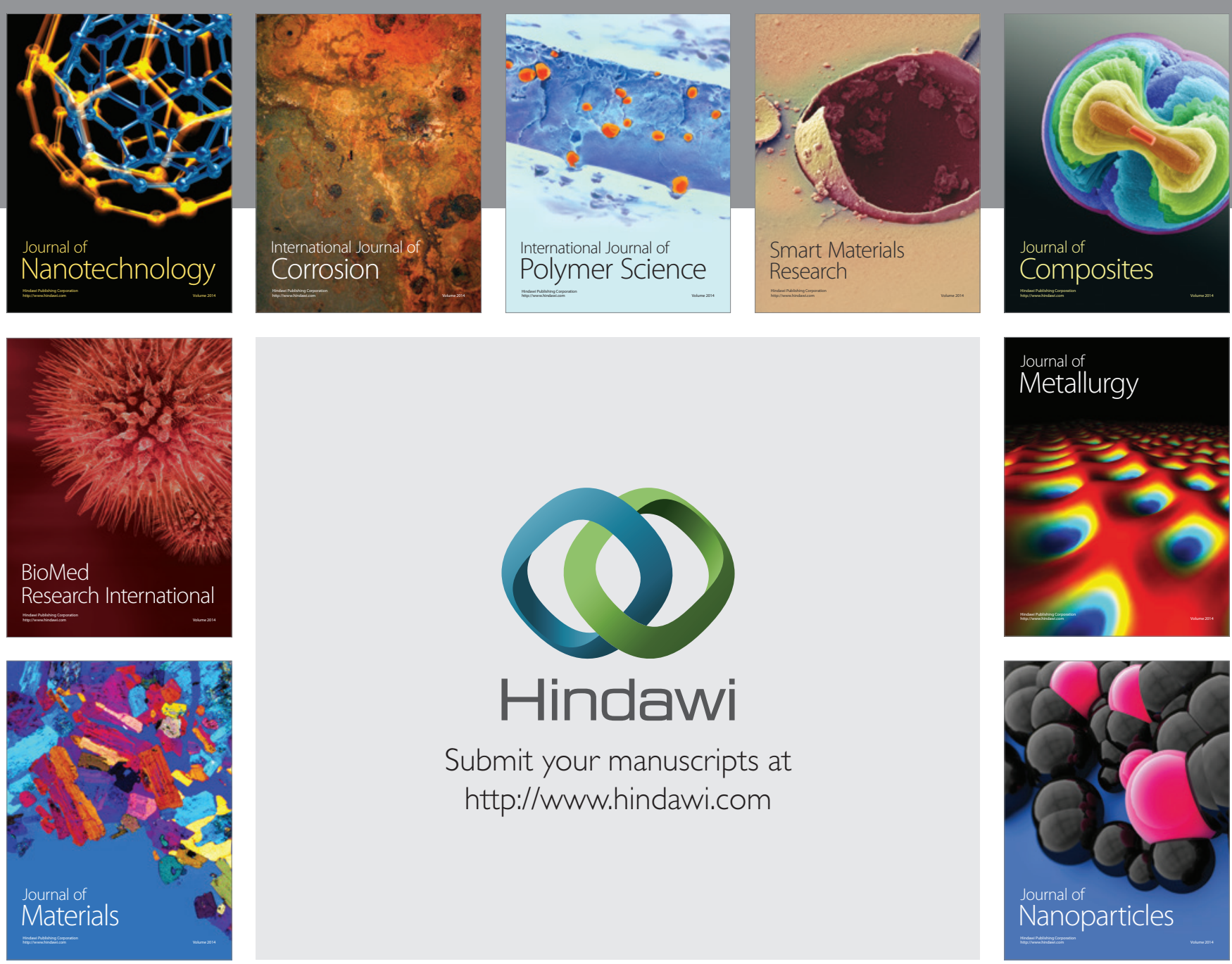

Submit your manuscripts at http://www.hindawi.com
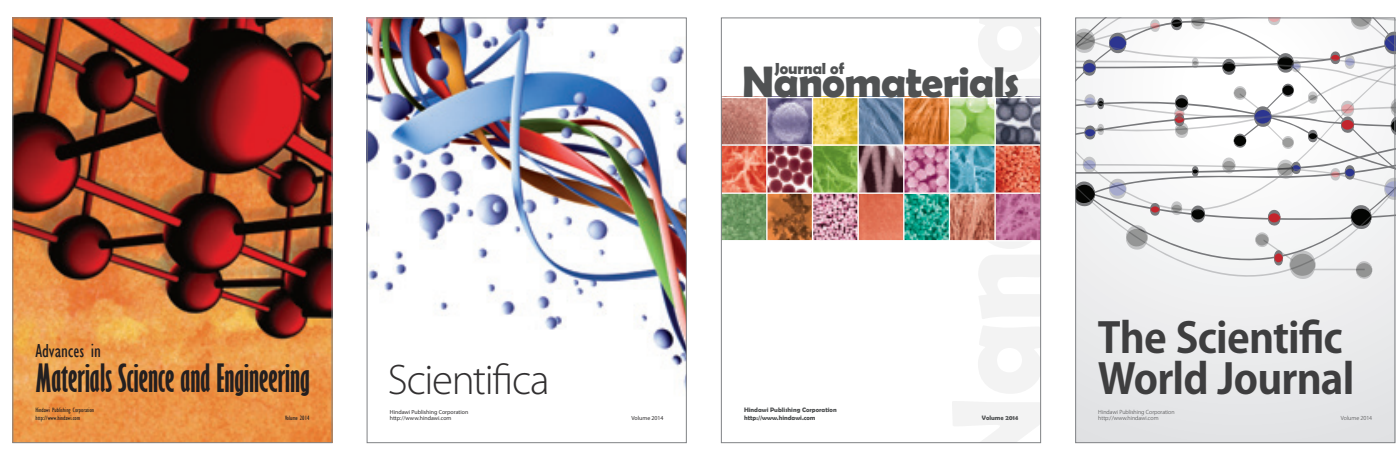

\section{The Scientific World Journal}
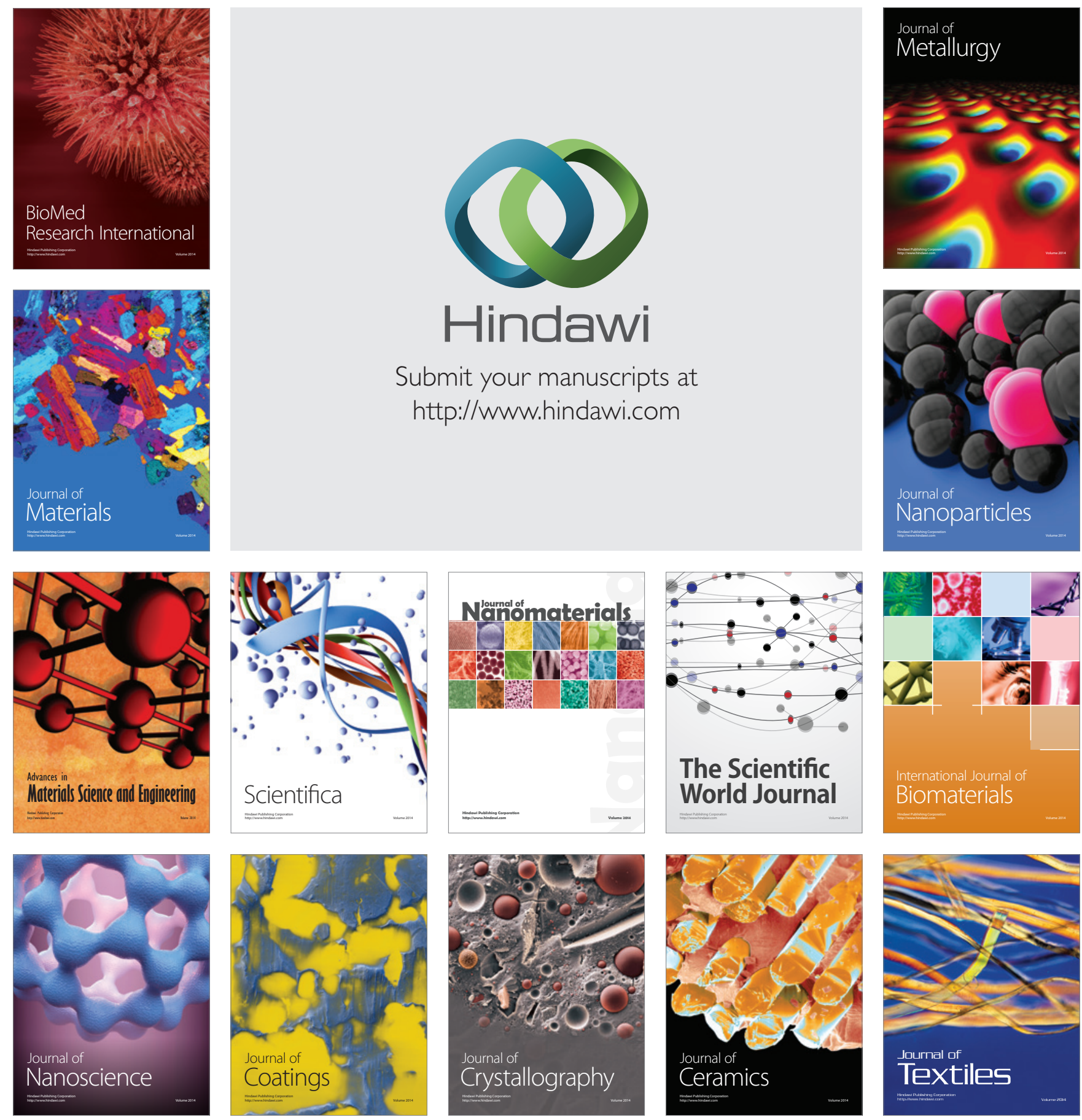